\title{
Left Ventricle Size, Qualitative
}

National Cancer Institute

\section{Source}

National Cancer Institute. Left Ventricle Size, Qualitative. NCI Thesaurus. Code C80421.

A descriptive characterization of the size of the left cardiac ventricle. 